stable in acid solution. Another possibility is the production of penicillins more suitable than peni. cillin $\mathrm{O}^{10}$ (allylmercaptomethylpenicillin) for the treatment of people who are sensitive to benzylpenicillin.

G. F. NewToN

${ }^{1}$ Sheehan, J. C., and Henery-Logan, K. R., J. Amer. Chem. Soc., 79, 1262 (1957).

${ }^{2}$ du Vigneaud, V., Carpenter, F. H., Holley, R. W., Livermore, A. H. and Rachele, J. R., "The Chemistry of Penicillin", 1018 (Princeton University Press, 1949).
${ }^{3}$ Sheehan, J. C., and Johnson, D. A., J. Amer. Chem. Soc., 76, 158 (1954).

${ }^{4}$ Sheehan, X. C., and Cruickshank, P. A., J. Amer. Chem. Soc., 78 3683 (1956). Sheehan, J. C., and Hoff, D. R., ibid., 79, 237 (1957) ${ }^{5}$ Sheehan, J. C., and Hess, G. P., J. Amer. Chem. Soc., 77, 1067 (1955). ${ }^{6}$ Khorana, H. G., Chem. and Indust., 1087 (1955).

${ }^{7}$ Brandl, E., and Margreiter, H., Osterr. Chem.-Ztg., 55, 11 (1954).

${ }^{8}$ Chem. and Eng. News, March 18, p. 32 (1957).

Abraham, E. P., and Newton, G. G. F., Biochem. J., 62, 658 (1956); 63, 628 (1956).

${ }^{10}$ Ford, J. H., Churchill, B. W., and Collingsworth, D. R., "Antibiotics and Chemotherapy", 3, 1149 (1953).

\title{
OBITUARIES
}

\section{Prof. George Gomori}

The death occurred on March 1 at Palo Alto, California, of Prof. George Gomori, at the age of fifty-three. He was one of the most original and productive investigators in the field of histochemistry over the past twenty years. There can be scarcely a journal on microscopical work to-day in which his contributions are not liberally quoted by workers all over the world. In contrast to his scientific renown, fow people in the United States, and still fewer from the British Commonwealth, had the privilege of knowing him well.

His main virtues as a man and investigator were a combination of great intellectual and practical versatility with a high degree of economy of his resources. Added to this was an unconcealed delight in the adventure of investigation, and a love of discovery altogether detached from thoughts of personal glory. Two of these qualities, the unselfish devotion to his work and the hatred of extravagance in any form, probably prevented many people who met him from recognizing his uniqueness. Gomori sacrificed everything to enable him to work smoothly and well.

The formal side of his career shows his versatility. As assistant to the professor of surgery in Budapest, he performed several thousand major operations, mostly under local anæsthesia. It is interesting to note that he had used his gastrectorny specimens for studying reticulum in peptic ulcer with the staining method which is now widely known by his name. It was a hardship for him to relinquish surgery on emigrating to the United States. A tidy technical ease was his outstanding characteristic as a laboratory worker, and it was the talent which he most loved to exercise as a surgeon. In America he re-qualified in medicine and became a registered pathologist, as well as professor of internal medicine (Chest Diseases Section) in the University of Chicago. His charming wife Margaret, as chief medical librarian, was always on the look-out for literature for him, and the four card-index drawers on his desk represented his most valuable literary asset in preparing papers and experiments. In his capacity as advising editor to several journals, it was no trouble to him to check the crucial observations in the articles submitted, or to detect a tiny flaw which would invalidate the conclusions. He never turned first to the summary of a paper, but would read the section on methods before anything else.

Although the days were mostly spent in his friendly little laboratory, apart from attendances at the clinic, Gomori gave the impression that work was more or less incidental. Sometimes prolonged silences would fall as his concentration increased, but he never appeared unduly engrossed or impatient of interruption. This was all part of his method.
His extreme personal simplicity and natural kindliness would deceive one about his tremendous store of experience in all branches of culture. He was an accomplished linguist. Having been cared for as a schoolboy by a Dutch clergyman when he was sent as a refugee in the First World War to Holland, he acquired a thorough knowledge of the Dutch language and literature, and an enduring love and gratitude towards the Dutch people. In philosophy he greatly admired Bertrand Russell. In music he was an excellent judge of singing, and spoke with critical admiration of European opera singers of the past, such as Jadlowker, Battistini, Jeritza and Piccaver.

His cultural attainments were a means to pleasure and insight, and were displayed only when strictly relevant. In a similar way, he never paraded or nursed his personal opinions on things and people. Whether favourable or unfavourable, his comments were brief and to the point and always tempered with tolerance and geniality.

Gomori did not frequently attend conferences and meetings, except those of the Histochemical Society. The benefits of meetings were too erratic to appeal to him. Perhaps for this reason we may lament some lack of direct personal recognition for his achievements, and regret the opportunities for granting him personal honour which the world has now lost. But of impersonal recognition he had an abundance, and enjoyed personal satisfaction without limit in his work itself.

G. H. Findrax

\section{Prof. Methods Popoff}

Referring to the obituary notice of Prof. Methodi Popoff in Nature of February 9, Dr. A. M. Young, of the World Federation of Scientific Workers, writes : "Prof. Popoff died in April 1954 and his body lay in state in the big hall of the Bulgarian Academy of Sciences for two days, during which many thousands of people paid him homage. The funeral took place on April 19, 1954, and was attended by representatives of the Bulgarian Government. So far as my information goes, Prof. Popoff's work was highly appreciated in his country and he received many awards and decorations, not only before the War but also after the founding of the People's Republie of Bulgaria in 1944. In 1950 he was awarded the highest Bulgarian distinction, the Dimitrov Prize (First Class), for his achievements in the field of stimulation. After his death the Institute of Biology, of which he had been director, was named the Methodi Popoff Institute of Biology. As late as 1953 there was an article by Prof. Popoff on his stimulation work in the English-language publication, Bulgaria 